\title{
Genomic Instability, Inflammation, and Cancer
}

\author{
Vassilis G. Gorgoulis \\ Department of Histology and Embryology, Medical School, University of Athens, 11527 Athens, Greece
}

Correspondence should be addressed to Vassilis G. Gorgoulis, vgorg@med.uoa.gr

Received 27 May 2012; Accepted 27 May 2012

Copyright ( 92012 Vassilis G. Gorgoulis. This is an open access article distributed under the Creative Commons Attribution License, which permits unrestricted use, distribution, and reproduction in any medium, provided the original work is properly cited.

Accumulating evidence supports that the inflammatory milieu plays a key role in the initiation and progression of epithelial cancer, the most characteristic example being that of ulcerative colitis which is associated with increased risk of colonic adenocarcinoma. Other less frequent and studied inflammatory lesions include asbestos-induced cellular damages, oral lichen planus (premalignant lesion), and cardiac myxoma. The mechanistic basis of this association is just beginning to be clarified. In the center of this picture lies the cytokine network which seems to link genomic instability, an evolving hallmark of cancer, with cancer development. In this special issue which deals with genomic instability, inflammation, and cancer, several research groups present evidence supporting this connection.

H. Matsuzaki et al. have demonstrated a relationship between chronic inflammation and carcinogenesis through asbestos-induced cellular and molecular alteration of immunocompetent cells, resulting in a decline in tumor immunity. Induction of chronic inflammation in the areas of the lung, regional lymph nodes and the pleural cavity has been shown to be due to the production of reactive oxygen/nitrogen species. Cellular and molecular features of immunocompetent cells may be altered by asbestos fibers which, combined with the surrounding inflammation, eventually lead to decreased tumor immunity.

M. Murata et al, have investigated the role of nitrative and oxidative DNA damage in inflammation-related carcinogenesis. In their work they revealed that infectious and noninfectious agents induce iNOS-dependent formation of 8-nitroguanine and 8-oxo-7,8-dihydro-2'-deoxyguanosine (8-oxodG) in cancer tissues and precancerous regions. Their results suggest that DNA base damage may lead to doublestranded breaks. They also demonstrated IL-6-modulated iNOS expression via STAT3 and EGFR in Epstein-Barr virusassociated nasopharyngeal carcinoma and found promoter hypermethylation in several tumor suppressor genes, while proposing 8-nitroguanine as potentially useful biomarkers for predicting the risk of inflammation-related cancers.

I. S. Pateras et al. have investigated the presence of herpes simplex virus (HSV) DNA in a cohort of cardiac myxomas assessing the possibility that HSV infection might be involved in the development of these lesions with potential therapeutic applications.

E. Georgakopoulou et al. have examined whether oral lichen planus exhibits malignant potential, with relation to the development of oral squamous cell carcinoma, and may therefore represent a model of preneoplastic inflammation.

I. Aivaliotis et al. have reviewed the effects of cytokines as crucial components of inflammation, participating in the interaction between the cells of the tumor microenvironment, and have focused on their potential role in the development of genomic instability.

This special issue of the Journal of Biomedicine and Biotechnology is devoted to the presentation of such inflammatory conditions with predisposition to genomic instability and cancer development. I hope that it will help stimulate research that is aimed at understanding and therapeutic targeting of these lesions.

Vassilis G. Gorgoulis 

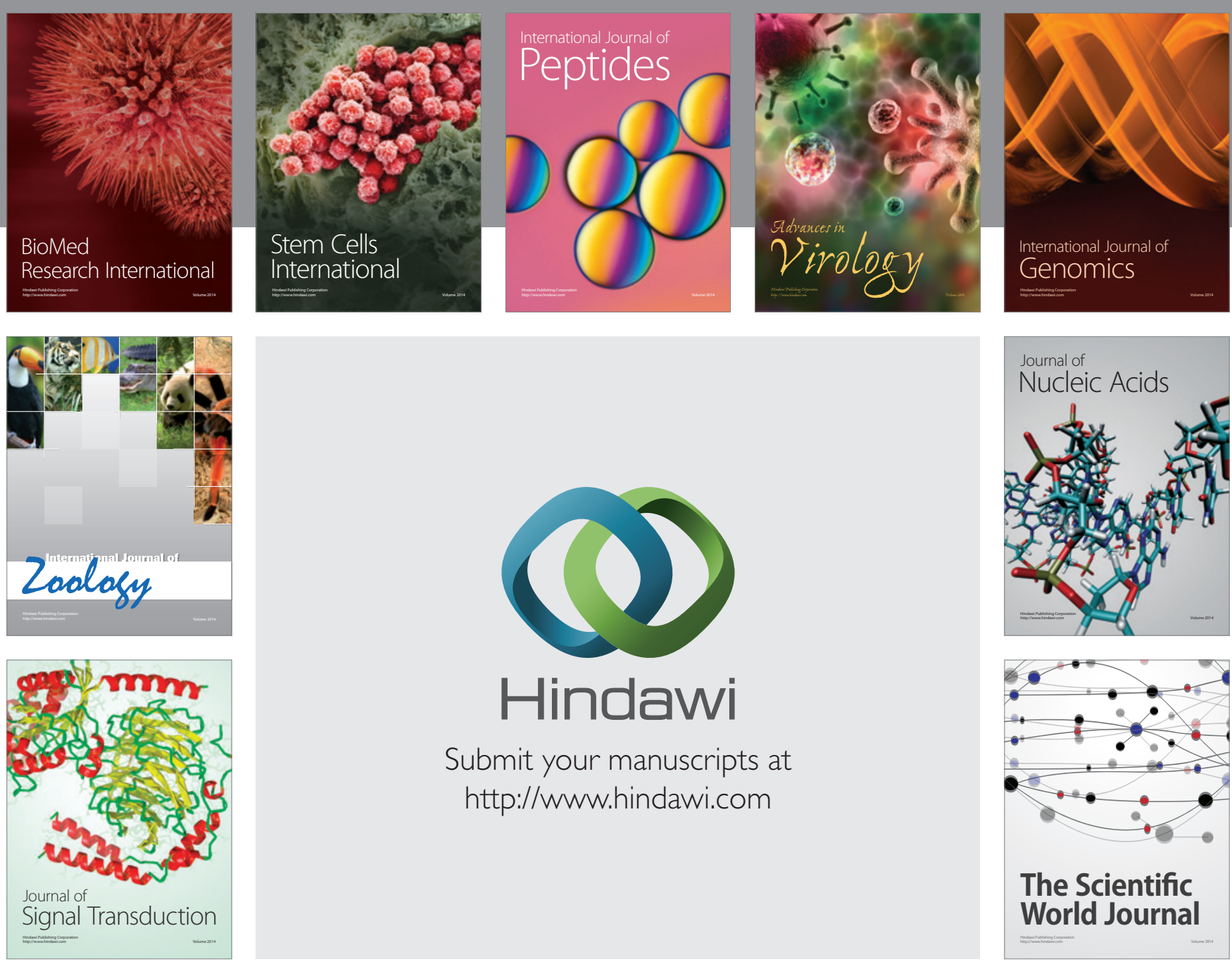

Submit your manuscripts at

http://www.hindawi.com
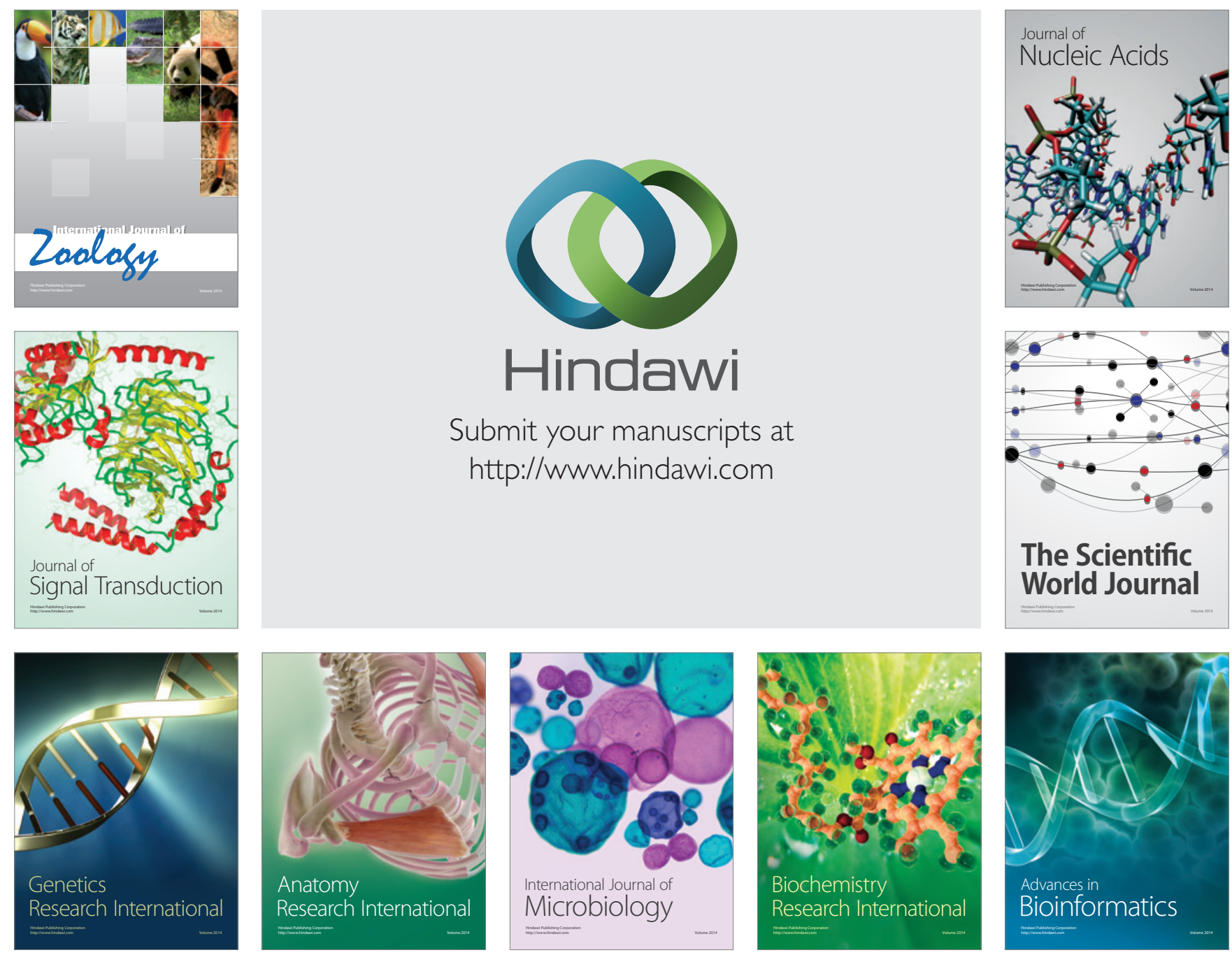

The Scientific World Journal
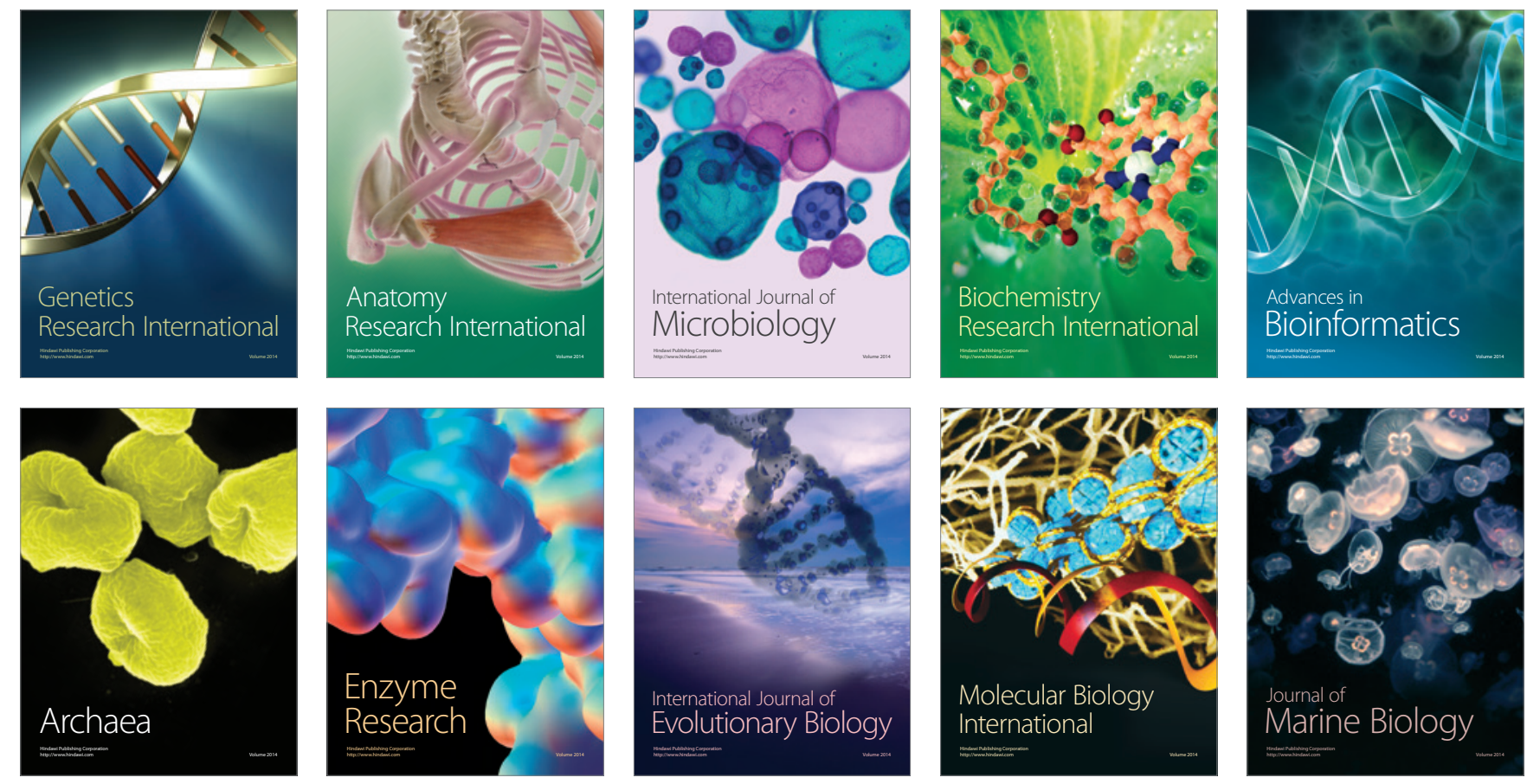